\title{
A medical costs study of older patients with acute myocardial infarction and metabolic syndrome in hospital
}

This article was published in the following Dove Press journal:

Clinical Interventions in Aging

23 January 2015

Number of times this article has been viewed

\author{
Guan-qi Fan' \\ Kai-li Fu' \\ Cheng-wei Jin' \\ Xiao-zhen Wang ${ }^{2}$ \\ Lu Han' \\ Hui Wang' \\ Ming Zhong' \\ Yun Zhang' \\ Wei Zhang' \\ Zhi-hao Wang ${ }^{1,3}$
}

'Key Laboratory of Cardiovascular Remodeling and Function Research, Chinese Ministry of Education and Chinese Ministry of Public Health, Department of Cardiology, Qilu Hospital of Shandong University, ${ }^{2}$ Shandong University of Traditional Chinese Medicine, ${ }^{3}$ Department of Geriatric Medicine, Qilu Hospital of Shandong University, Ji'nan, People's Republic of China
Correspondence: Wei Zhang Department of Cardiology, Qilu Hospital of Shandong University, 107 Wen Hua Xi Road, Ji'nan 2500I2, People's Republic of China Tel +86 53। 82169339 Fax +86 53। 86169356

Email weizhangsdu@।26.com

Zhi-hao Wang

Department of Geriatric Medicine, Qilu Hospital of Shandong University, 107 Wen Hua Xi Road, Ji'nan 2500I2, People's Republic of China Tel +8653182169339

$\mathrm{Fax}+8653186169356$

Email wangzhihaosdu@।26.com
Background: Older patients with acute myocardial infarction (AMI) usually have a poor prognosis, but whether this poor prognosis leads to high hospital costs remains unclear. This study investigated the clinical outcomes of and costs incurred by older patients with AMI and metabolic syndrome (MS) in hospital.

Methods and results: Patients with AMI seen at Qilu Hospital of Shandong University between January 2011 and May 2013 were separated into four groups: young non-MS patients $(n=282)$, older non-MS patients $(n=324)$, young MS patients $(n=217)$, and older MS patients $(n=174)$. We found that advanced age was significantly associated with worse clinical outcomes, and that the clinical outcomes in patients with AMI and MS are also worsened. At the same cost (RMB $¥ 10,000$ ), older patients with and without MS had a markedly increased number of cardiovascular incidences compared with younger patients without MS. In a comparison of the incremental cost-effectiveness ratio (ICER) of percutaneous coronary intervention, older patients without MS had a lower ICER for cardiovascular incidences and a higher ICER for cardiac event-free survival rate when compared with young patients without MS, but a lower ICER for cardiovascular incidences and a higher ICER for cardiac event-free survival rate when compared with older MS patients.

Conclusion: Older AMI patients have poor clinical outcomes and their treatment is not costeffective; however, the results are worse in patients with AMI and MS. Percutaneous coronary intervention is a cost-effective therapy in older patients with AMI, but its cost-effectiveness decreases in patients with AMI and MS.

Keywords: metabolic syndrome, aging, vascular, acute myocardial infarction, costeffectiveness

\section{Introduction}

As one of the largest populated countries in the world, the People's Republic of China is facing serious problems associated with aging. According to the Chinese National Bureau of Statistics, the number of people aged 65 years and older increased to 127 million in 2012, representing approximately $9.4 \%$ of the total population of the People's Republic of China. Moran et al reported that aging and population growth will increase rates of cardiovascular disease by more than a half in the next 20 years in the People's Republic of China, ${ }^{1}$ which will be accompanied by a tremendous economic burden.

Acute myocardial infarction (AMI) is one of the most deadly of the cardiovascular diseases. Mortality following AMI increases exponentially with age, and is associated with clinical features that vary according to age. Older patients are more likely to have a "silent" or unrecognized AMI and to develop heart failure, atrial fibrillation, cardiac 
rupture, and shock, all of which are associated with increased mortality and a poor prognosis. ${ }^{2,3}$ However, whether the medical costs of older AMI patients increases is not known.

The rapidly evolving management of patients with AMI over recent decades has led to improved survival rates. ${ }^{4-6}$ Although doctors seek more clinical effectiveness, which is always costly, patients seek effective but inexpensive management, leading to cost-effectiveness issues. Percutaneous coronary intervention (PCI) is proven to be an effective treatment for coronary artery disease. However, because of their clinical features and concerns about PCI, older AMI patients are less likely to undergo this procedure. ${ }^{7}$ Studies show that PCI can decrease the risk of complications and improve the prognosis ${ }^{8-10}$ in older patients with AMI. In such situations, it is important to determine whether existing therapies are cost-effective.

A recent study has shown that there is a high and rapidly growing incidence of metabolic syndrome (MS) in the elderly Chinese population. ${ }^{11}$ It is also known that MS is associated with a poor prognosis in AMI patients. ${ }^{12-15}$ Thus, it would be worthwhile to determine if clinical outcomes are worse and associated with increased hospital costs in elderly patients with both AMI and MS. To answer this question, we reviewed the case files of patients admitted with AMI to Qilu Hospital of Shandong University between January 2011 and May 2013 and analyzed their clinical outcomes and hospital costs.

\section{Methods}

\section{Ethics statement}

This research was approved by the ethics committee of Qilu Hospital of Shandong University. Written informed consent was given by the participants for their clinical records to be used in this study. All data were anonymized and deidentified prior to analysis.

\section{Case file collection}

We identified the case files of consecutive patients with a discharge diagnosis of AMI at Qilu Hospital of Shandong University between January 2011 and May 2013. In total, 1,150 patients were included. Information taken from these case files included sex, height, weight, diagnosis on admission, discharge diagnosis, duration of hospital stay, hospital costs, history of smoking, past medical illness, family medical history, laboratory examination, coronary arteriography, cardiac ultrasound, complications, and drug treatment.

\section{Definition of MS}

Metabolic syndrome was defined by the Chinese Diabetes Society criteria as the presence of three or all of the following four characteristics: overweight and/or obesity (body mass index $\geq 0.25 \mathrm{~kg} / \mathrm{m}^{2}$ ); hyperglycemia (fasting plasma glucose $\geq 6.1 \mathrm{mmol} / \mathrm{L}$ and postprandial glucose $\geq 7.8 \mathrm{mmol} / \mathrm{L}$, and/or diagnosed diabetes mellitus receiving treatment); hypertension (systolic/diastolic blood pressure $\geq 140 / 90 \mathrm{mmHg}$, and/or the diagnosed hypertension receiving treatment); and lipid disorder (triglycerides $\geq 1.7 \mathrm{mmol} / \mathrm{L}$ and/or high-density lipoprotein cholesterol $<0.9 \mathrm{mmol} / \mathrm{L}$ for males or $<1.0 \mathrm{mmol} / \mathrm{L}$ for females).

\section{Grouping}

We defined older patients as those aged older than 65 years. The patients with AMI were separated to four elderlyMS groups, ie, young non-MS patients ( $\mathrm{n}=282)$, older non-MS patients $(n=324)$, young MS patients $(n=217)$, and older MS patients $(n=174)$. One hundred and fifty-three cases could not be categorized because of inadequate information.

\section{Statistical analysis}

All analyses were conducted using Statistical Package for the Social Sciences version 18.0 software (SPSS Inc., Chicago, IL, USA) and $P<0.05$ was considered to be statistically significant. The results are expressed as the mean \pm standard deviation or as a proportion (\%). For categorical variables, the $\chi^{2}$ test was used. Analysis of variance was used to study the impact of age and MS on duration of hospital stay and costs. Multiple linear regressions using the stepwise method were performed to examine predictors of hospital costs. Binary logistic regressions using the forward conditional method were performed to examine individual predictors of acute heart failure, atrial arrhythmia, ventricular arrhythmia, and death in hospital.

\section{Cost-effectiveness analysis}

The formula used to calculate the cost-effectiveness ratio (CER) is as follows:

$$
\mathrm{CER}=\frac{\mathrm{P}}{\mathrm{C}}
$$

where $\mathrm{P}$ is the rate of complication and $\mathrm{C}$ is the mean total cost. The formula used to calculate the incremental costeffectiveness ratio (ICER) is as follows:

$$
\mathrm{ICER}=\frac{\Delta \mathrm{P}}{\Delta \mathrm{C}}=\frac{\mathrm{P}_{1}-\mathrm{P}_{0}}{\mathrm{C}_{1}-\mathrm{C}_{0}}
$$

where $\mathrm{P}_{1}$ is the complication rate with $\mathrm{PCI}, \mathrm{C}_{1}$ represents the mean total costs of PCI, $\mathrm{P}_{0}$ is the complication rate without $\mathrm{PCI}$, and $\mathrm{C}_{0}$ is the mean total cost without PCI. 


\section{Results}

\section{Baseline data}

Table 1 shows the admission and treatment information for the elderly-MS groups. Significant differences were found between the different elderly-MS groups for all variables except serum potassium and use of aspirin and angiotensinconverting enzyme inhibitors.

\section{Hospital stay and costs}

Table 2 shows the analysis of variance results for hospital stay and costs in the elderly-MS groups. Hospital stay, total costs, daily costs, medical treatment costs, laboratory investigation costs, and tablet costs were significantly different between the four groups. Analysis of variance showed that patient age, but not MS, had a significant impact on duration of hospital stay and costs. There was no age-MS interaction in the models. Age is an influential factor, and we found that older AMI patients had longer hospital stays, more laboratory investigation costs, and tablet costs, but lower total costs, daily costs, and medical treatment costs.

\section{Major cardiovascular events}

Table 3 shows the complication rates and cardiac event-free survival rates in hospital for the elderly-MS groups. Increased age was associated with a significantly higher rate of acute heart failure as well as atrial and ventricular arrhythmia, and a low cardiac event-free survival rate. However, the relationship between increasing age and a higher risk of death did not reach statistical significance. Similarly, there was no statistically significant relationship when MS was considered. However, in patients with both AMI and MS, increased age led to more obvious differences when compared with older non-MS patients. We also analyzed individual predictors of acute heart failure, atrial arrhythmia, ventricular arrhythmia, and death (Table S1).

Figure 1 shows the CER for different aspects of cardiovascular events in the elderly-MS groups. At the same cost of RMB $¥ 10,000$, young MS patients had a similar or slightly higher rate of cardiovascular incidences than young non-MS patients, and the latter had the lowest rate of cardiovascular incidences; in contrast, older non-MS patients and older MS patients both had a higher rate of cardiovascular incidences compared with young non-MS patients. With regard to cardiac event-free survival, older non-MS patients had the highest CER at $18.8 \%$, which decreased to $15.8 \%$ in older MS patients.

\section{Cost-effectiveness of $\mathrm{PCl}$}

Table 4 shows that body mass index and PCI are major predictors of total costs and daily costs. To examine whether
PCI is a cost-effective therapy, we calculated the ICER for PCI.

Figure 2 shows the ICER for PCI in different aspects of cardiovascular events in the elderly-MS groups. With an extra RMB $¥ 10,000$ in young non-MS patients, rates of acute heart failure and death decreased by $0.3 \%$ and $0.1 \%$, respectively. Atrial arrhythmia and ventricular arrhythmia both increased by $0.6 \%$, and cardiac event-free survival rate did not change. With an extra RMB $¥ 10,000$ in older non-MS patients, rates of acute heart failure decreased by $5.1 \%$, atrial arrhythmia by $1.6 \%$, ventricular arrhythmia by $2.1 \%$, and death by $0.7 \%$, and cardiac event-free survival increased by $3.9 \%$. With an extra RMB $¥ 10,000$ in young MS patients, acute heart failure decreased by $2.9 \%$, atrial arrhythmia by $0.7 \%$, and death by $0.8 \%$, while the ventricular arrhythmia rate did not change and cardiac event-free survival increased by $4.0 \%$. With an extra RMB $¥ 10,000$ in older MS patients, acute heart failure decreased by $2.6 \%$, atrial arrhythmia by $0.7 \%$, ventricular arrhythmia by $0.9 \%$, and death by $1.7 \%$, while cardiac eventfree survival increased by $2.8 \%$.

The ICER value for older non-MS patients was smaller than that for young non-MS patients when considering acute heart failure, atrial arrhythmia, ventricular arrhythmia, and death. However, the ICER for older non-MS patients was higher than that for young non-MS patients when considering cardiac event-free survival. These results mean adverse cardiovascular events decrease more and cardiac event-free survival increases more in older non-MS patients. Similarly, when we compared the ICER for PCI between older non-MS and older MS patients, we found that adverse cardiovascular events, with the exception of death, decrease less and cardiac event-free survival increases less in older MS patients.

\section{Discussion}

In this study, we found that older AMI patients had longer hospital stays and more laboratory investigations, examination costs, and tablet costs, but lower total costs, daily costs, and medical treatment costs. For the same total costs, older AMI patients had a higher complication rate, which is more obvious when AMI is combined with MS. PCI is cost-effective in older patients with AMI, but this effect is partly offset in patients with both AMI and MS.

We observed that AMI patients aged younger than 65 years were more likely to be males. In addition, younger patients had more of a smoking history and family history of hypertension, diabetes, coronary heart disease, and stroke compared with older patients. Increased triglycerides and decreased high-density lipoprotein, as main components of MS, were apparent in young AMI patients. All of these 
Table I Comparison of baseline characteristics of AMI patients in different elderly-MS groups

\begin{tabular}{|c|c|c|c|c|c|}
\hline & $\begin{array}{l}\text { Young non-MS patients } \\
(\mathrm{n}=\mathbf{2 8 2})\end{array}$ & $\begin{array}{l}\text { Older non-MS patients } \\
(n=324)\end{array}$ & $\begin{array}{l}\text { Young MS patients } \\
(n=2 \mid 7)\end{array}$ & $\begin{array}{l}\text { Older MS patients } \\
(n=174)\end{array}$ & $P$-value \\
\hline Age (years) & $53.18 \pm 8.54$ & $75.58 \pm 6.5 \mathrm{I}$ & $53.82 \pm 8.01$ & $74.34 \pm 6.06$ & $<0.001$ \\
\hline Male sex, n (\%) & $239(84.8)$ & $194(59.9)$ & $182(83.9)$ & $82(47.1)$ & $<0.001$ \\
\hline BMI $\left(k g / m^{2}\right)$ & $24.72 \pm 3.77$ & $22.84 \pm 3.58$ & $27.53 \pm 2.94$ & $26.89 \pm 2.97$ & $<0.00$ I \\
\hline $\mathrm{SBP}(\mathrm{mmHg})$ & $122.00 \pm 18.37$ & $|3| .|4 \pm 2| .43$ & $|32.4| \pm 22.47$ & $|38.20 \pm 2| .08$ & $<0.00$ I \\
\hline $\mathrm{DBP}(\mathrm{mmHg})$ & $74.10 \pm 12.27$ & $73.43 \pm 11.84$ & $80.27 \pm 14.75$ & $77.06 \pm 12.35$ & $<0.001$ \\
\hline HR (bpm) & $75.13 \pm 12.95$ & $77.54 \pm 18.21$ & $79.50 \pm 17.17$ & $77.32 \pm 15.93$ & 0.028 \\
\hline Smoking history, n (\%) & $179(63.5)$ & II 4 (35.2) & $140(64.5)$ & 45 (25.9) & $<0.001$ \\
\hline \multicolumn{6}{|l|}{ Past medical history } \\
\hline Hypertension, n (\%) & $73(25.9)$ & $170(52.5)$ & $162(74.7)$ & $150(86.2)$ & $<0.001$ \\
\hline Diabetes, n (\%) & $25(8.9)$ & $63(19.4)$ & $103(47.5)$ & $110(63.2)$ & $<0.001$ \\
\hline CAD, n (\%) & $122(43.3)$ & $185(57.1)$ & $105(48.4)$ & $107(6 \mid .5)$ & $<0.001$ \\
\hline Stroke, n (\%) & $14(5.0)$ & $60(18.5)$ & $33(15.2)$ & $45(25.9)$ & $<0.001$ \\
\hline \multicolumn{6}{|l|}{ Family history } \\
\hline Hypertension, n (\%) & $58(20.6)$ & $33(10.2)$ & $67(30.9)$ & $27(15.5)$ & $<0.001$ \\
\hline Diabetes, n (\%) & $19(6.7)$ & $8(2.5)$ & $26(12.0)$ & $7(4.0)$ & $<0.00$ I \\
\hline CAD, n (\%) & $60(21.3)$ & $20(6.2)$ & $59(27.2)$ & $12(6.9)$ & $<0.001$ \\
\hline Stroke, n (\%) & $23(8.2)$ & $7(2.2)$ & II (5.I) & $6(3.4)$ & 0.005 \\
\hline \multicolumn{6}{|l|}{ Laboratory investigations } \\
\hline Cholesterol (mmol/L) & $4.39 \pm 1.07$ & $4.55 \pm 1.13$ & $4.79 \pm 1.18$ & $4.69 \pm 1.23$ & 0.001 \\
\hline $\mathrm{TG}(\mathrm{mmol} / \mathrm{L})$ & $1.46 \pm 1.03$ & $1.09 \pm 0.53$ & $2.17 \pm 1.25$ & $1.75 \pm 0.85$ & $<0.001$ \\
\hline $\mathrm{HDL}(\mathrm{mmol} / \mathrm{L})$ & $I .11 \pm 0.24$ & $1.21 \pm 0.25$ & $1.01 \pm 0.24$ & $1.23 \pm 0.23$ & $<0.001$ \\
\hline LDL (mmol/L) & $2.76 \pm 0.94$ & $2.8 I \pm 0.88$ & $3.03 \pm 0.96$ & $2.93 \pm 0.92$ & 0.006 \\
\hline NEFA $(\mu \mathrm{mol} / \mathrm{L})$ & $60.17 \pm 33.39$ & $69.34 \pm 30.87$ & $63.72 \pm 31.15$ & $72.79 \pm 35.60$ & 0.008 \\
\hline PLIP (mmol/dL) & $2 .|4 \pm 0.4|$ & $2.21 \pm 0.47$ & $2.34 \pm 0.53$ & $2.26 \pm 0.54$ & 0.006 \\
\hline Glucose (mmol/L) & $5.93 \pm 2.94$ & $5.85 \pm 2.25$ & $7.33 \pm 2.64$ & $7.68 \pm 3.01$ & $<0.001$ \\
\hline ALT (U/L) & $47.89 \pm 39.10$ & $33.16 \pm 60.33$ & $42.64 \pm 42.85$ & $37.85 \pm 65.79$ & 0.006 \\
\hline AST (U/L) & $99.54 \pm 130.11$ & $67.71 \pm 86.15$ & $77.89 \pm 104.95$ & $70.44 \pm 126.86$ & 0.003 \\
\hline BUN (mmol/L) & $4.79 \pm 2.84$ & $5.82 \pm 3.24$ & $5.42 \pm 3.67$ & $6.73 \pm 3.32$ & $<0.001$ \\
\hline $\mathrm{Cr}(\mu \mathrm{mol} / \mathrm{L})$ & $71.70 \pm 29.18$ & $82.01 \pm 62.18$ & $80.20 \pm 77.23$ & $93.62 \pm 54.65$ & 0.001 \\
\hline Cys-c (mg/L) & $0.93 \pm 0.26$ & $1.19 \pm 0.59$ & $0.98 \pm 0.49$ & $1.32 \pm 0.74$ & 0.001 \\
\hline $\mathrm{UA}(\mu \mathrm{mol} / \mathrm{L})$ & $299.27 \pm 81.06$ & $303.76 \pm 107.58$ & $326.48 \pm 84.26$ & $319.01 \pm 110.48$ & 0.006 \\
\hline $\mathrm{K}(\mathrm{mmol} / \mathrm{L})$ & $4.09 \pm 0.41$ & $3.98 \pm 0.51$ & $4.18 \pm 2.02$ & $4.12 \pm 0.68$ & 0.160 \\
\hline Urine protein, n (\%) & $2(0.9)$ & $23(8.5)$ & $12(7.1)$ & $21(14.2)$ & $<0.00$ I \\
\hline \multicolumn{6}{|l|}{ Treatment } \\
\hline Stent implantation, $\mathrm{n}(\%)$ & $211(74.8)$ & $122(37.7)$ & $142(65.4)$ & $81(46.6)$ & $<0.001$ \\
\hline $\begin{array}{l}\text { Twice revascularization, } \\
\mathrm{n}(\%)\end{array}$ & $19(6.7)$ & $8(2.5)$ & $21(9.7)$ & $6(3.4)$ & 0.001 \\
\hline Aspirin, n (\%) & $278(98.6)$ & $310(95.7)$ & $213(98.2)$ & I 72 (98.9) & 0.065 \\
\hline $\begin{array}{l}\text { ADP receptor } \\
\text { antagonist, } n(\%)\end{array}$ & $279(98.9)$ & $295(91.0)$ & $214(98.6)$ & $170(97.7)$ & $<0.001$ \\
\hline Beta-blocker, n (\%) & $222(78.7)$ & $242(74.7)$ & $184(84.8)$ & | 47 (84.5) & 0.010 \\
\hline ACEI, n (\%) & $116(41.1)$ & $135(4 \mid .7)$ & $101(46.5)$ & $64(36.8)$ & 0.277 \\
\hline ARB, n (\%) & $82(29.1)$ & $124(38.3)$ & $87(40.1)$ & $94(54.0)$ & $<0.001$ \\
\hline Statins, n (\%) & $270(95.7)$ & $283(87.3)$ & $211(97.2)$ & I59 (9I.4) & $<0.001$ \\
\hline CCB, n (\%) & 39 (13.8) & $81(25.0)$ & $57(26.3)$ & $64(36.8)$ & $<0.00$ I \\
\hline Diuretic, n (\%) & $35(12.4)$ & $126(38.9)$ & $47(21.7)$ & $74(42.5)$ & $<0.001$ \\
\hline
\end{tabular}

Note: Data are shown as mean \pm SD unless otherwise stated.

Abbreviations: AMI, acute myocardial infarction; BMI, body mass index; SBP, systolic blood pressure; DBP, diastolic blood pressure; HR, heart rate; CAD, coronary artery disease; TG, triglycerides; HDL, high-density lipoprotein; LDL, low-density lipoprotein; NEFA, nonesterified fatty acids; PLIP, phospholipids; ALT, alanine aminotransferase; AST, aspartate aminotransferase; BUN, blood urea nitrogen; $\mathrm{Cr}$, creatinine; Cys-c, cystatin C; UA, uric acid; ACEl, angiotensin-converting enzyme inhibitor; ADP, adenosine diphosphate; ARB, adrenergic receptor blocker; CCB, calcium channel blocker; MS, metabolic syndrome; SD, standard deviation. 
Table 2 Comparison of hospital stays and costs of AMI patients in different elderly-MS groups

\begin{tabular}{|c|c|c|c|c|c|c|c|c|}
\hline & $\begin{array}{l}\text { Young non-MS } \\
\text { patients } \\
(\mathrm{n}=282)\end{array}$ & $\begin{array}{l}\text { Older non-MS } \\
\text { patients } \\
(n=324)\end{array}$ & $\begin{array}{l}\text { Young MS } \\
\text { patients } \\
(n=2 \mid 7)\end{array}$ & $\begin{array}{l}\text { Older MS } \\
\text { patients } \\
(n=174)\end{array}$ & $P$ & PI & $\mathbf{P 2}$ & P3 \\
\hline Hospital stay (days) & $10.85 \pm 4.29$ & $13.24 \pm 6.89$ & $11.08 \pm 5.58$ & $|2.83 \pm 6.7|$ & $<0.001$ & 0.820 & $<0.001$ & 0.410 \\
\hline Total costs $\left(\times 10^{3} \mathrm{RMB} ¥\right)$ & $55.44 \pm 27.97$ & $40.07 \pm 30.26$ & $52.00 \pm 31.74$ & $44.44 \pm 34.18$ & $<0.001$ & 0.816 & $<0.001$ & 0.051 \\
\hline Daily costs $\left(\times 10^{3}\right.$ RMB $\left.¥\right)$ & $6.03 \pm 5.69$ & $3.74 \pm 4.26$ & $5.84 \pm 5.94$ & $4.02 \pm 3.49$ & $<0.001$ & 0.884 & $<0.001$ & 0.472 \\
\hline Medical treatment costs $\left(\times 10^{3} \mathrm{RMB} ¥\right)$ & $20.6 \mathrm{I} \pm 26.03$ & $12.03 \pm 21.12$ & $19.65 \pm 26.83$ & $12.51 \pm 21.60$ & $<0.001$ & 0.878 & $<0.001$ & 0.646 \\
\hline Chemical investigation costs ( $\left.\times 10^{3} \mathrm{RMB} ¥\right)$ & $1.64 \pm 0.76$ & $2.14 \pm 1.31$ & $1.76 \pm 0.91$ & $2.17 \pm 1.44$ & $<0.001$ & 0.339 & $<0.001$ & 0.527 \\
\hline Tablet costs $\left(\times 10^{3}\right.$ RMB $\left.¥\right)$ & $11.76 \pm 6.86$ & $13.76 \pm 10.16$ & $11.72 \pm 7.56$ & $14.20 \pm 9.64$ & $<0.001$ & 0.723 & $<0.001$ & 0.674 \\
\hline
\end{tabular}

Notes: $P$, significance of corrected model; $P$ I, significance of MS; $P 2$, significance of age; $P 3$, significance of MS*age. Data are shown as mean \pm SD.

Abbreviations: AMI, acute myocardial infarction; MS, metabolic syndrome; SD, standard deviation.

suggest male sex, smoking history, family history of cardiovascular disease, and dyslipidemia are risk factors in young patients with AMI. ${ }^{16-18}$

Our results show that older patients with AMI had longer hospital stays but lower total costs. At baseline, older patients with AMI had high levels of blood urea nitrogen, creatinine, cystatin $\mathrm{C}$, uric acid, and urinary protein, indicating poor renal function which may account for their longer hospital stays. There are reports in the literature showing that the duration of hospital stay in patients with AMI is associated with PCI, complications, and sex. ${ }^{19,20}$ Our results show that PCI is the main factor influencing hospital costs in patients with AMI, which is in accordance with other reports..$^{21,22}$ The lower PCI rate in older patients with AMI may account for their lower total costs.

The impact of MS on hospital stay and costs in patients with AMI has not been well reported. Our results show that MS did not result in longer hospital stays and lower total costs in patients with AMI. The reason could be that the impact of each MS component on AMI is different, which may counterbalance the total effect.

We found that older AMI patients were more likely to experience cardiovascular complications and less likely to survive free of cardiac events, which is in agreement with previous research. ${ }^{23} \mathrm{We}$ evaluate the cost-effectiveness of management in AMI patients at Qilu Hospital of Shandong University using a CER comparison. We found that older
non-MS patients had a higher CER in terms of complications and cardiac event-free survival, it was difficult to determine whether the management in older non-MS patients is costeffective. We presume that management of older non-MS patients is cost-effective, but this cost-effectiveness decreases when complications of AMI occur. Older MS patients had a high CER in terms of complications and a low CER in terms of cardiac event-free survival, suggesting that management in older MS patients is not cost-effective. In other words, MS decreases the cost-effectiveness of management in older patients with AMI.

Our results show that PCI is cost-effective in older patients and those with MS, and the cost-effectiveness decreases when the two factors are combined, while the cost-effectiveness of PCI compared with that of drug therapy is equal in young non-MS patients with AMI. These results help to inform patients about the cost-effectiveness of PCI in their particular circumstances. There has been a recent report showing that female AMI patients aged younger than 40 years have a higher long-term mortality rate than their male counterparts after $\mathrm{PCI},{ }^{24}$ suggesting that the effectiveness of PCI in young AMI patients is sex-related. However, how sex influences the cost-effectiveness of PCI in AMI patients needs further investigation.

Our study has several limitations. Firstly, it was a retrospective observational study, so we could not determine the

Table 3 Comparison of complication rates in AMI patients at hospital for different elderly-MS groups

\begin{tabular}{|c|c|c|c|c|c|}
\hline Group & $\begin{array}{l}\text { Acute heart failure } \\
\text { n (\%) }\end{array}$ & $\begin{array}{l}\text { Atrial arrhythmia } \\
\text { n (\%) }\end{array}$ & $\begin{array}{l}\text { Ventricular arrhythmia } \\
\text { n (\%) }\end{array}$ & $\begin{array}{l}\text { Death } \\
\text { n (\%) }\end{array}$ & $\begin{array}{l}\text { Cardiac event-free } \\
\text { survival n (\%) }\end{array}$ \\
\hline Young non-MS patients & $6(2.1)$ & $4(1.4)$ & $16(5.7)$ & $3(1.1)$ & $258(9 \mid .5)$ \\
\hline Older non-MS patients & $41(12.7)^{* \dagger}$ & $34(10.5)^{* \dagger}$ & $28(8.6)$ & $7(2.2)$ & $244(75.3)^{* \dagger}$ \\
\hline Young MS patients & $12(5.5)$ & $8(3.7)$ & $9(4.1)$ & $2(0.9)$ & $190(87.6)$ \\
\hline Older MS patients & $19(10.9)^{*}$ & $22(12.6)^{*+}$ & $24(13.8)^{* \dagger}$ & $7(4.0)$ & $122(70.1)^{* \dagger}$ \\
\hline$P$-value & $<0.001$ & $<0.001$ & 0.003 & 0.115 & $<0.001$ \\
\hline
\end{tabular}

Notes: $* P<0.05$ versus young non-MS patients; ${ }^{\dagger} P<0.05$ versus MS.

Abbreviations: AMI, acute myocardial infarction; MS, metabolic syndrome. 
A

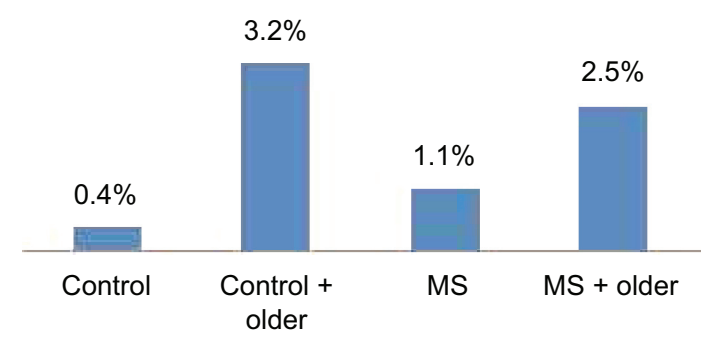

C

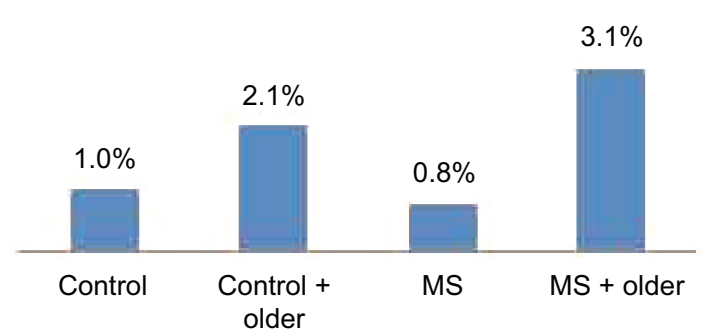

B

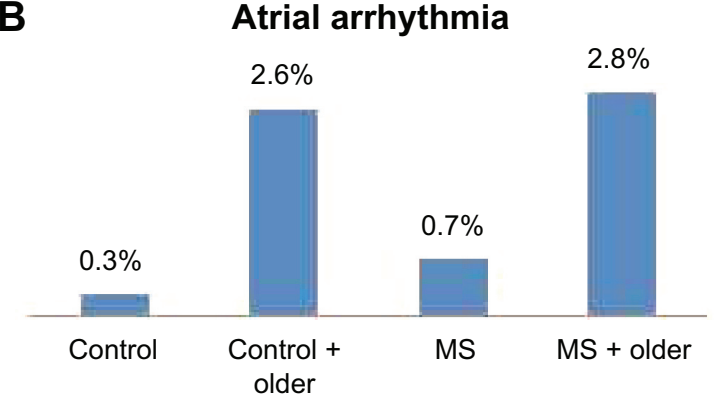

D

\section{Death}

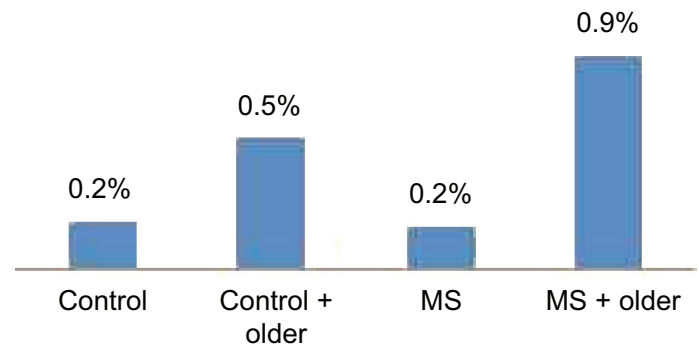

E

Event-free survival

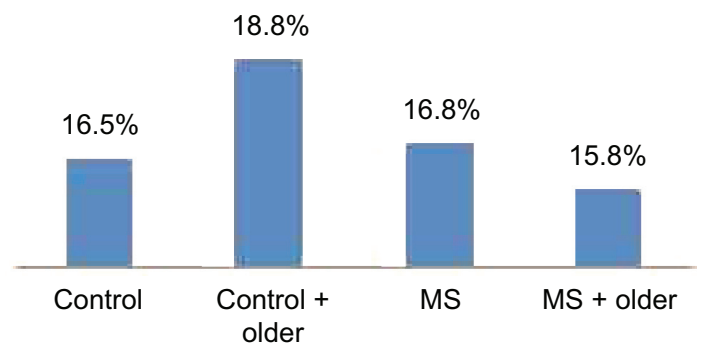

Figure I Comparison of CER in different aspects of cardiovascular events in the elderly-MS groups.

Notes: $C E R=P / C$, where $P$ is the rate of complication and $C$ is the mean total costs $\left(\times 10^{4} \mathrm{RMB} ¥\right)$. Group control indicates young non-MS patients with AMI. Group control + older indicates older non-MS patients with AMI. Group MS indicates young MS patients with AMI. Group MS + older indicates older MS patients with AMI.

Abbreviations: AMI, acute myocardial infarction; CER, cost-effectiveness ratio; MS, metabolic syndrome.

Table 4 Multiple linear regression analysis of costs in AMI patients

\begin{tabular}{llll}
\hline & $\boldsymbol{\beta}$ & $\boldsymbol{P}$-value & $\boldsymbol{R}^{\mathbf{2}}$ \\
\hline Total costs & & & \\
BMI & 0.526 & $<0.00 \mathrm{I}$ & 0.684 \\
PCI & 0.315 & $<0.00 \mathrm{I}$ & $0.73 \mathrm{I}$ \\
Urinary protein & 0.130 & $<0.00 \mathrm{I}$ & $0.75 \mathrm{I}$ \\
Twice revascularization & 0.104 & $0.00 \mathrm{I}$ & 0.760 \\
Ventricular arrhythmia & 0.083 & 0.012 & 0.765 \\
Daily costs & & & \\
BMI & 0.469 & $<0.001$ & 0.520 \\
PCI & $0.35 \mathrm{I}$ & $<0.00 \mathrm{I}$ & 0.578 \\
\hline
\end{tabular}

Abbreviations: $\mathrm{BMI}$, body mass index; $\mathrm{PCl}$, percutaneous coronary intervention; AMl, acute myocardial infarction. long-term disease costs in older patients with AMI. Secondly, with no patients having coronary artery bypass grafting, we could not compare the cost-effectiveness of this procedure with that of PCI. Thirdly, there was a potential for selection bias in this single-center study.

\section{Conclusion}

Older AMI patients have poor clinical outcomes and costeffectiveness, and the results are even worse in patients with AMI and MS. PCI is a cost-effective therapy in older non-MS patients with AMI, but the cost-effectiveness decreases in patients with a combination of AMI and MS. 

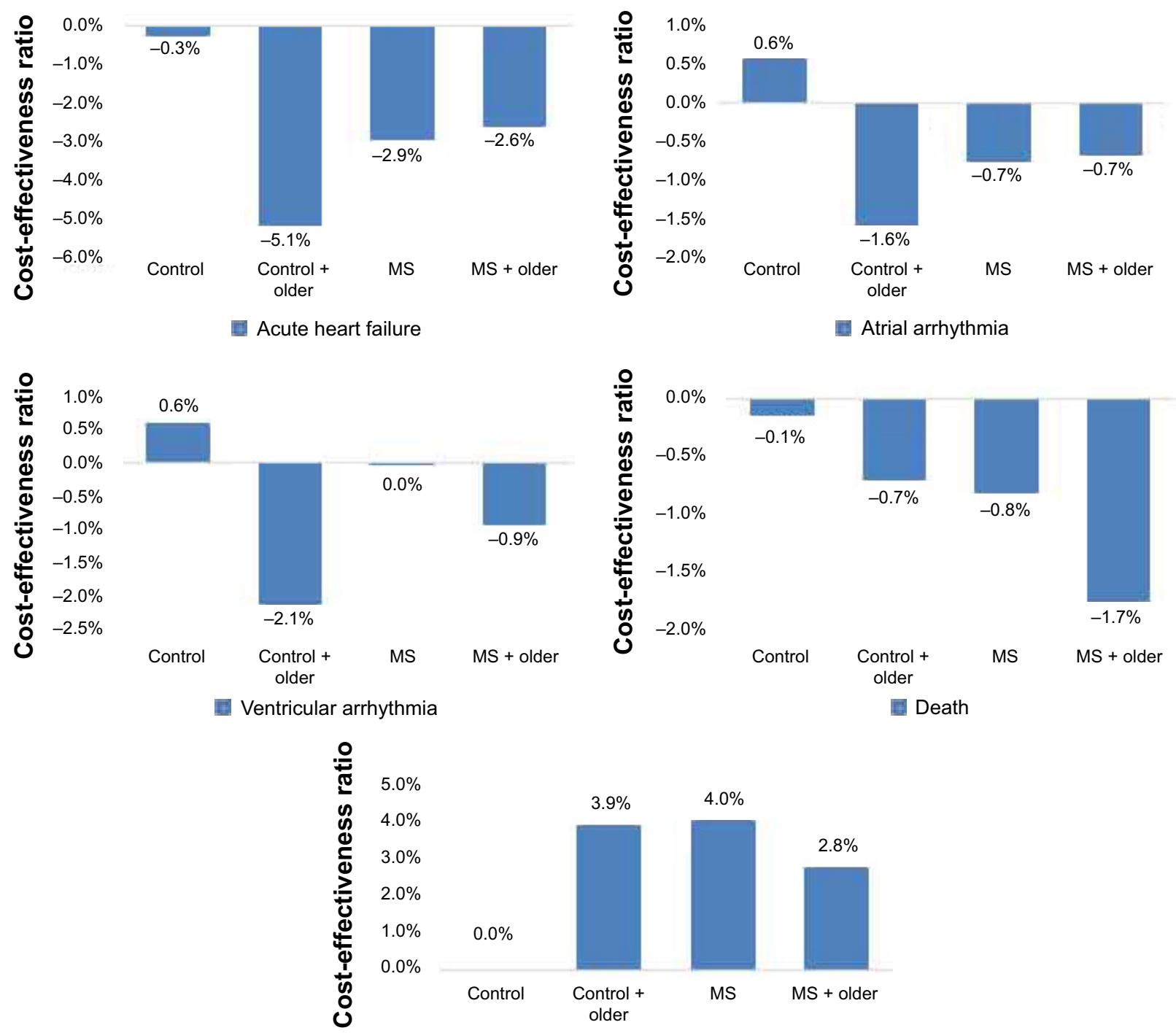

Incident-free survival

Figure 2 Comparison of incremental cost-effectiveness ratio of $\mathrm{PCl}$ in different aspects of cardiovascular events in the elderly-MS groups.

Notes: ICER $=\Delta \mathrm{PI} / \mathrm{C}=\left(\mathrm{P}_{1}-\mathrm{P}_{0}\right) /\left(\mathrm{C}_{1}-\mathrm{C}_{0}\right) . \mathrm{P}_{0}$ represents the complication rate without $\mathrm{PCl}$ and $\mathrm{P}_{1}$ represents the complication rate with $\mathrm{PCl}, \mathrm{C}_{0}$ represents mean total costs $\left(\times 10^{4} \mathrm{RMB} ¥\right)$ without $\mathrm{PCl}$, and $\mathrm{C}$, represents mean total costs $\left(\times 10^{4} \mathrm{RMB}\right)$ with $\mathrm{PCl}$. Group control indicates young non-MS patients with AMI. Group control + older indicates older non-MS patients with AMI. Group MS indicates young MS patients with AMI. Group MS + older indicates older MS patients with AMI.

Abbreviations: AMI, acute myocardial infarction; MS, metabolic syndrome; PCI, percutaneous coronary intervention; ICER, incremental cost-effectiveness ratio.

\section{Acknowledgments}

This work was supported by research grants from the National Basic Research Program of China (973 Program, 2013CB530700), the National Natural Science Foundation of China (81070192, 81070141, 81100605, 81270352 , and 81270287), the Natural Science Foundation of Shandong Province (BS2013YY017), the Independent Innovation Foundation of Shandong University (2012JC034), and the Cardiovascular Exploration Research Foundation of the Chinese Medical Doctor Association (DFCMDA201320).

\section{Disclosure}

The authors report no competing interests in this work.

\section{References}

1. Moran A, Gu D, Zhao D, et al. Future cardiovascular disease in China: Markov model and risk factor scenario projections from the coronary heart disease policy model-China. Circ Cardiovasc Qual Outcomes. 2010;3(3):243-252.

2. Rich MW. Epidemiology, clinical features, and prognosis of acute myocardial infarction in the elderly. Am J Geriatr Cardiol. 2006;15(1): $7-11$.

3. Gregoratos G. Clinical manifestations of acute myocardial infarction in older patients. Am J Geriatr Cardiol. 2001;10(6):345-347. 
4. Masoudi FA, Foody JM, Havranek EP, et al. Trends in acute myocardial infarction in 4 US states between 1992 and 2001: clinical characteristics, quality of care, and outcomes. Circulation. 2006;114(25): 2806-2814.

5. Goldberg RJ, Spencer FA, Yarzebski J, et al. A 25-year perspective into the changing landscape of patients hospitalized with acute myocardial infarction (the Worcester Heart Attack Study). Am J Cardiol. 2004;94(11):1373-1378.

6. Filsoufi F, Rahmanian PB, Castillo JG, Chikwe J, Silvay G, Adams DH. Results and predictors of early and late outcomes of coronary artery bypass graft surgery in octogenarians. J Cardiothorac Vasc Anesth. 2007; 21(6):784-792.

7. Kala P, Kanovsky J, Rokyta R, et al. Age-related treatment strategy and long-term outcome in acute myocardial infarction patients in the PCI era. BMC Cardiovasc Disord. 2012;12:31.

8. Pagé M, Doucet M, Eisenberg MJ, Behlouli H, Pilote L. Temporal trends in revascularization and outcomes after acute myocardial infarction among the very elderly. CMAJ. 2010;182(13):1415-1420.

9. Sakai K, Nagayama S, Ihara K, et al. Primary percutaneous coronary intervention for acute myocardial infarction in the elderly aged $\geq 75$ years. Catheter Cardiovasc Interv. 2012;79(1):50-56.

10. Birkemeyer R, Rillig A, Treusch F, et al. Outcome and treatment quality of transfer primary percutaneous intervention in older patients with acute ST-elevation myocardial infarction (STEMI). Arch Gerontol Geriatr. 2011;53(3):259-262.

11. Liu M, Wang J, Jiang B, et al. Increasing prevalence of metabolic syndrome in a Chinese elderly population: 2001-2010. PLoS One. 2013; 8(6):e66233.

12. Zeller M, Steg PG, Ravisy J, et al; Observatoire des Infarctus de Côted'Or Survey Working Group. Prevalence and impact of metabolic syndrome on hospital outcomes in acute myocardial infarction. Arch Intern Med. 2005;165(10):1192-1198.

13. Lee MG, Jeong MH, Ahn Y, et al. Impact of the metabolic syndrome on the clinical outcome of patients with acute ST-elevation myocardial infarction. J Korean Med Sci. 2010;25(10):1456-1461.

14. Bari MA, Islam MS, Paul GK, Chanda SK, Siddique SR, Khan TA. Metabolic syndrome is a risk factor for development of heart failure in acute myocardial infarction. Mymensingh Med J. 2012;21(4):633-638.
15. Ji MS, Jeong MH, Ahn Y, et al; Other Korea Acute Myocardial Infarction Registry Investigators. One-year clinical outcomes among patients with metabolic syndrome and acute myocardial infarction. Korean Circ J. 2013;43(8):519-526.

16. Chua SK, Hung HF, Shyu KG, et al. Acute ST-elevation myocardial infarction in young patients: 15 years of experience in a single center. Clin Cardiol. 2010;33(3):140-148.

17. Teo KK, Ounpuu S, Hawken S, et al; INTERHEART Study Investigators. Tobacco use and risk of myocardial infarction in 52 countries in the INTERHEART study: a case-young non-MS patients study. Lancet. 2006;368(9536):647-658.

18. Huang J, Qian HY, Li ZZ, Zhang JM. Comparison of clinical features and outcomes of patients with acute myocardial infarction younger than 35 years with those older than 65 years. Am J Med Sci. 2013;346(1): $52-55$.

19. Vavalle JP, Lopes RD, Chen AY, et al. Hospital length of stay in patients with non-ST-segment elevation myocardial infarction. Am J Med. 2012; 125(11):1085-1094.

20. Every NR, Spertus J, Fihn SD, Hlatky M, Martin JS, Weaver WD. Length of hospital stay after acute myocardial infarction in the Myocardial Infarction Triage and Intervention (MITI) Project registry. J Am Coll Cardiol. 1996;28(2):287-293.

21. Etemad LR, McCollam PL. Predictors of high-cost managed care patients with acute coronary syndrome. Curr Med Res Opin. 2005; 21(12):1977-1984.

22. Häkkinen U, Hartikainen J, Juntunen M, Malmivaara A, Peltola M, Tierala I. Analysing current trends in care of acute myocardial infarction using PERFECT data. Ann Med. 2011;43 Suppl 1:S14-S21.

23. Medina HM, Cannon CP, Zhao X, et al. Quality of acute myocardial infarction care and outcomes in 33,997 patients aged 80 years or older: findings from Get With The Guidelines-Coronary Artery Disease (GWTG-CAD). Am Heart J. 2011;162(2):283-290.

24. Sadowski M, Janion-Sadowska A, Gąsior M, Gierlotka M, Janion M, Poloński L. Higher mortality in women after ST-segment elevation myocardial infarction in very young patients. Arch Med Sci. 2013;9(3): 427-433. 


\section{Supplementary material}

Table SI Logistic regression analysis of individual predictors of acute heart failure, atrial arrhythmia, ventricular arrhythmia, and death in elderly AMI patients

\begin{tabular}{|c|c|c|c|c|}
\hline Predictor & $\beta$ & $P$-value & OR & $95 \% \mathrm{Cl}$ \\
\hline \multicolumn{5}{|l|}{ Acute heart failure } \\
\hline NEFA & 0.012 & 0.041 & 1.012 & $1.000-1.023$ \\
\hline Stent implantation & -1.274 & 0.016 & 0.280 & $0.100-0.785$ \\
\hline Hemoglobin & -0.021 & $<0.001$ & 0.979 & $0.972-0.987$ \\
\hline \multicolumn{5}{|l|}{ Atrial arrhythmia } \\
\hline Urinary protein & 1.630 & 0.002 & 5.106 & $1.865-13.980$ \\
\hline PLIP & -0.967 & $<0.001$ & 0.380 & $0.311-0.465$ \\
\hline \multicolumn{5}{|l|}{ Ventricular arrhythmia } \\
\hline Glucose & 0.187 & 0.004 & 1.206 & $1.060-1.37 \mid$ \\
\hline Urinary protein & 1.568 & 0.007 & 4.796 & $1.542-14.920$ \\
\hline $\mathrm{HDL}$ & -1.910 & $<0.001$ & 0.148 & $0.059-0.374$ \\
\hline Statin & -1.833 & $<0.001$ & 0.160 & $0.058-0.44 \mid$ \\
\hline \multicolumn{5}{|l|}{ Death } \\
\hline Diabetes & 2.947 & 0.020 & 19.043 & $1.605-225.992$ \\
\hline Hemoglobin & -0.015 & 0.034 & 0.985 & $0.972-0.999$ \\
\hline Beta blocker & -3.864 & 0.006 & 0.021 & $0.00 \mathrm{I}-0.325$ \\
\hline ARB & -2.929 & 0.046 & 0.053 & $0.003-0.953$ \\
\hline Aspirin & -2.990 & 0.034 & 0.050 & $0.003-0.800$ \\
\hline
\end{tabular}

Abbreviations: AMI, acute myocardial infarction; NEFA, nonesterified fatty acids; PLIP, phospholipids; HDL, high-density lipoprotein; ARB, adrenergic receptor blocker; $\mathrm{Cl}$, confidence interval; OR, odds ratio.

\section{Publish your work in this journal}

Clinical Interventions in Aging is an international, peer-reviewed journal focusing on evidence-based reports on the value or lack thereof of treatments intended to prevent or delay the onset of maladaptive correlates of aging in human beings. This journal is indexed on PubMed Central, MedLine,
CAS, Scopus and the Elsevier Bibliographic databases. The manuscript management system is completely online and includes a very quick and fair peer-review system, which is all easy to use. Visit http://www.dovepress. $\mathrm{com} /$ testimonials.php to read real quotes from published authors. 